\title{
MASS HOUSING FOR SQUATTER SETTLEMENTS USING PRE-CUT BAMBOO BUILDING SYSTEMS
}

\author{
Arne Zucker \\ Dipl.-Ing. \\ Am Grenzgraben 21, 85232 Bergkirchen \\ arne.zucker@web.de
}

\author{
Thomas Bock \\ Prof. Dr.-Ing./ Univ.Tokio \\ Arcisstr.21, 80333 München \\ thomas.bock@bri.ar.tum.de
}

\begin{abstract}
Aesthetics is not 'something out of this world' that happens in 'Parises' and 'New Yorks' and 'Bombays' and at exorbitant prices." (Vinoo Kaley, cp. "Build your House").

The current work tries to improve, to embellish and to simplify life for slum dwellers by creating a module system for their housing needs. It can be prefabricated, but it can also easily constructed, developed and enlarged by the inhabitants themselves.
\end{abstract}

\section{PROBLEM AND TASKS}

The problem of squatters in Bombay is the unplanned manner which destroys future possibilities of development and improvement. It is better to know already different possible last steps when you start with a settlement to keep all opportunities open.

One key to this is urbanism. It is possible to modify afterwards the structure or materials of a single house but it is very difficult to change the urban layout once it is fixed. The houses in this layout should be based on a modular principle so that the settlers can develop their own living space step by step according to their needs and finances.

The most expensive good in Bombay is land, followed with distance by materials. Labour however is very cheap. So the first aim is to use the space very economically, secondary the use of material.

\section{DEFINITION}

In colonies with low rise and high density there are basically row houses with common walls. This is very economically in the use of space and material. The question is how to design these rows.

I want to discuss three possibilities.
In variant $\mathrm{A}$ the houses have a path and doors on both sides, but a main orientation to only one side. In type $\mathrm{B}$ there is a big way in front of two houses and a smaller one on their back. Variant $\mathrm{C}$ has two rows together with three common walls for each house and one big path in the middle.

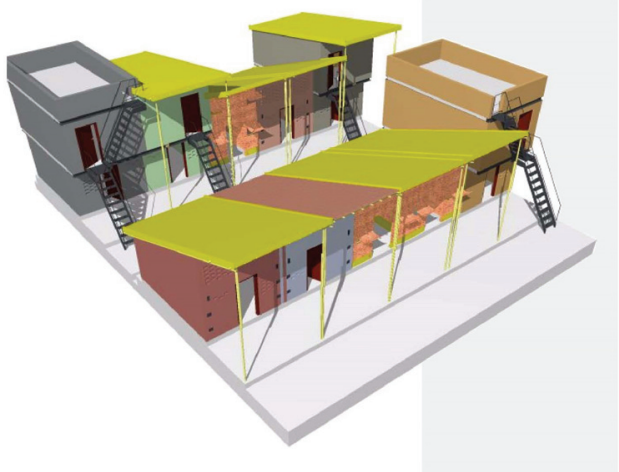

\section{POSITIVE AND NEGATIVE ASPECTS}

The airflow is best in A. in type B you require a wind collecting roof which might not work very well and which also costs material and maintenance. In type $\mathrm{C}$ there is no airflow. It can be provided only with a fan. 
The common space is best in B because you have two rows together which generate an ensemble with their roofs. In $\mathrm{C}$ the roofs do not form this unity; in A there is first of all the community of only one row.

On the other hand the problem of B is its back passage will become a very, very dirty area. In these colonies people often do not feel responsible, for consequences the waste and excrements might become the reason for an epidemic disease one day. That is why I discard this solution. In A and C there are no back passages. They have always a main entrance where everyone feels responsible.

If there is a fire you have only one direction to escape in $\mathrm{C}$, in A and B there are two.

Concerning the space requirement $\mathrm{C}$ is most economic; A needs larger area for each hut. But if you have two rows on one way the path should be wider (what is often not done). In A you have best opportunities for extension in the first floor in the $3^{\text {rd }}$ or $4^{\text {th }}$ step.

The use of materials is best in $C$ because you can share three walls. In A and B you share only two. But the third side is the smaller one.

All the three solutions can work on a sloping plot.

The possibilities for drainage are very bad in $\mathrm{C}$ because you have only one way and it reduces the width of the path very much- especially if it is open in the beginning. In B you can use the back passage but this will become more and dirtier. In A you have best possibilities. You can have one drainage line for each row of houses. They can be constructed easily under ground later.

Overall the best choice is A because it has natural ventilation, precludes dirty areas and has the possibility of extension in the first floor in the $3^{\text {rd }}$ or $4^{\text {th }}$ step. Most common in squatters is $\mathrm{C}$ because of its economical use of the plot.

One unit in A requires about 25 sqm (including public way). If you suppose an average density of 5 persons/ hut and 400 plots/ha, you have 2000 people/ha in the first step and 4000 people/ha in the third or fourth when you build the first floor. Of course you require also open public space and places, so there are less than 400 plots on a hectare.

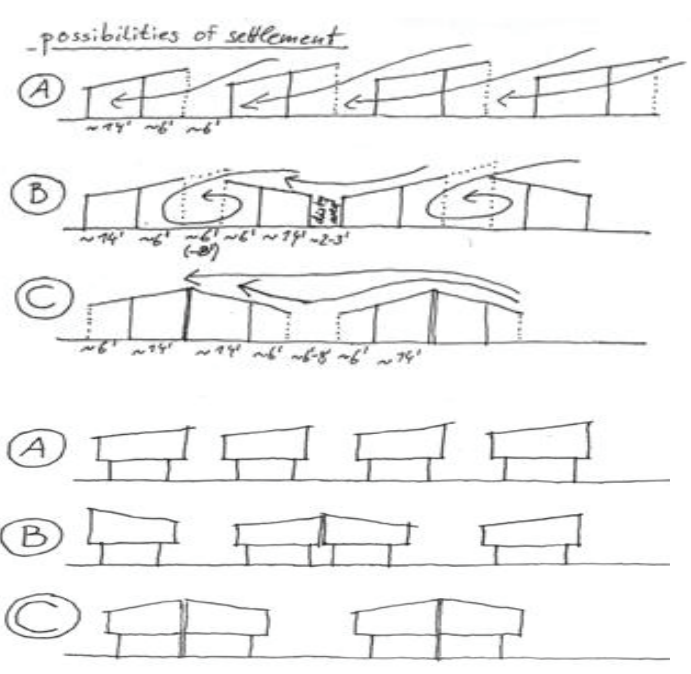

\section{ORIENTATION}

The orientation should correspond to the main wind direction and to the sun. The wind comes usually from southwest; the sun affects the houses on the roofs and the east and west side. In consequence best orientation means east-west rows with north/south oriented houses. The sun protected main entrance in $\mathrm{A}$ is on the south side to allow the wind coming in.

\section{URBAN COMPOSITION}

One row consists of five to seven houses; three to five rows are one unit; several units compose a colony. The units are very strict and economical in the space use. The public open spaces and facilities are around the units- depending on the needs and possibilities.
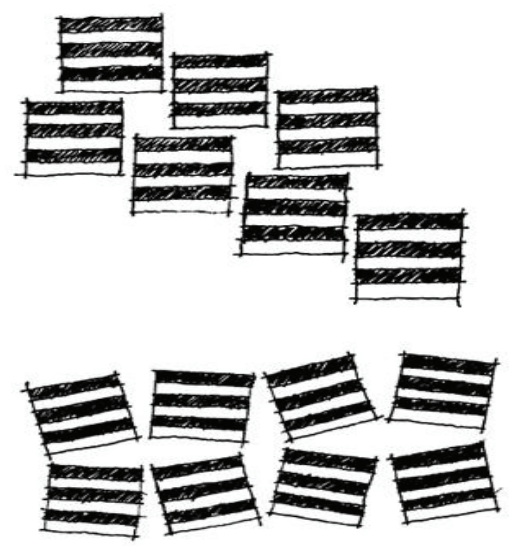
Their layout can be made more interesting by breaking regularity to avoid monotony. Every unit should be connected to a bigger street to give access to the fire brigade and to the police. Furthermore there is parking space required.

\section{DESIGN}

A big problem for squatter settlers is the fact that they don't have regular work and income. So there are planned verandas in front of the houses to give them the possibility to produce something and to work at home. These verandas are monsoon protected with a roof. The walls can be replaced by grills to protect property against theft but to allow airflow. If they employed for regular income outside the colony, there can be more people accommodated in this space if necessary. It also can be rented out if there is a big distress. What is more, there should be trees planted on the corners of this space. Inside the hut there is a toilet combined with a shower. It is an Indian WC in the floor where you can put down a wire mesh to stand for a shower. Next to this is a "nahni"- a typical
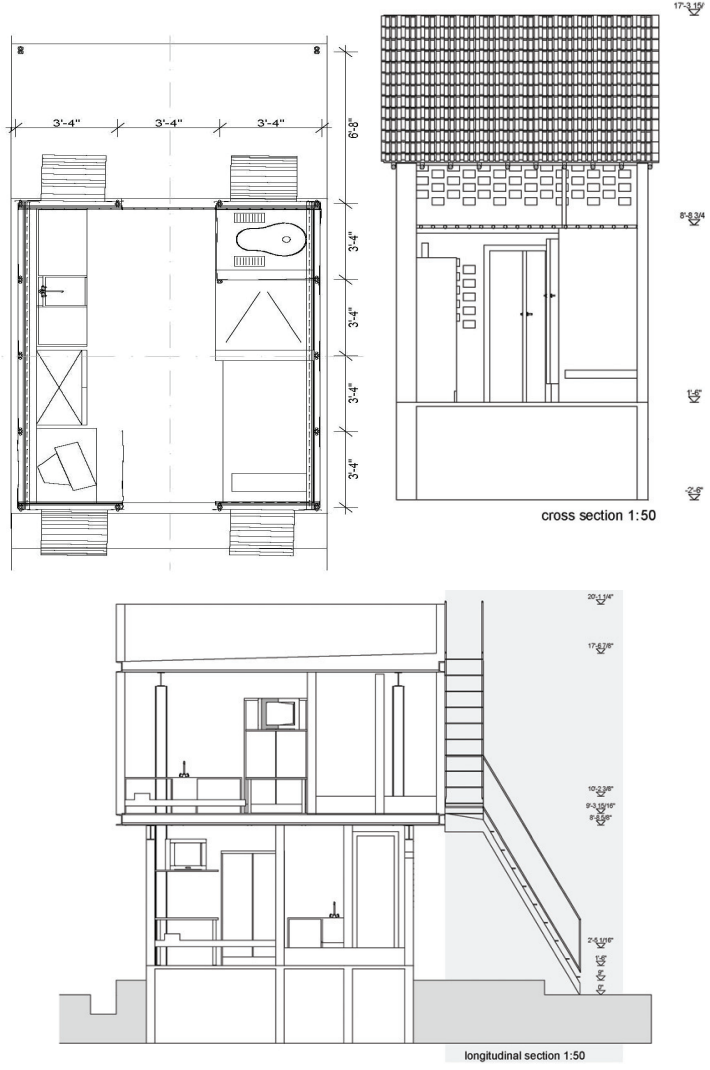

Indian washing opportunity for washing e.g. clothes or dishes, but also for having a shower. It is better to have two separate rooms because you can use both for having a shower if there is a rush. The kitchen should be as far away as possible from the toilet to avoid epidemics.

On the back side of the hut there is a small semipublic space of 1'-2' to have a distance between the way and the house and its windows to create a little privacy. There the settlers can make some small-farming or just have a bank to sit down. Below it there can be the drainage.
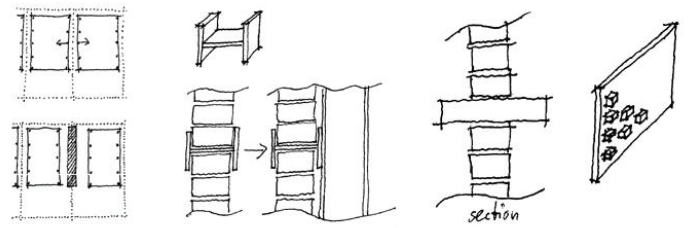

\section{MATERIALS AND SCHEDULE}
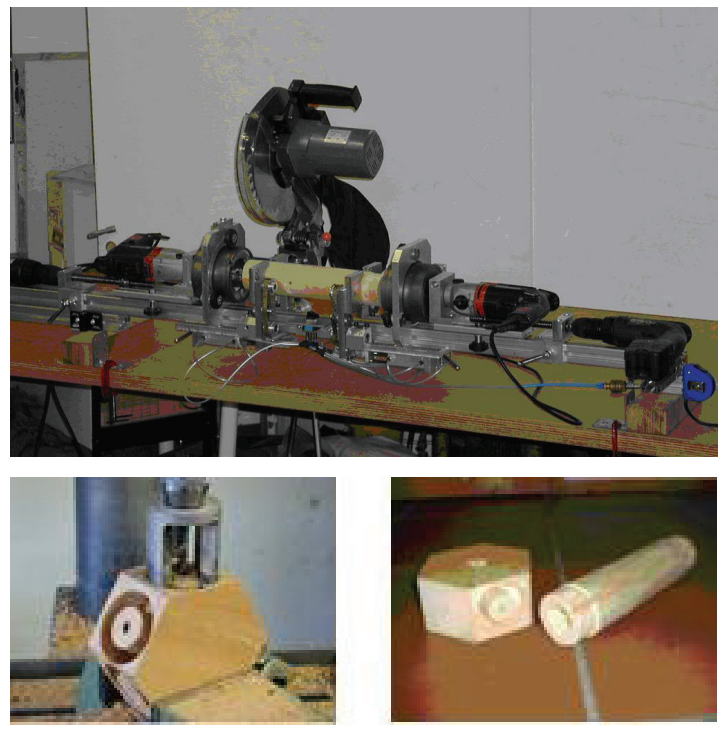

The system is developed modular. The units can be prefabricated; the setting up is done by the inhabitants themselves. For a mass production the nodal points can be improved by standardization and the using of a milling cutter. The mass production will cut costs of the single connection also for low budget requirements. The advantage will be the better quality and security. Renzo Piano experimented also with bamboo connections in 
1997 (cp. "Grow your own House", Vitra Des. Museum).

\section{TEMPORARY SHELTER}

Sometimes it is sure that you require only a temporary shelter- e.g. for building workers who live on the site during construction or for residents of areas in rehabilitation. In these cases you have a transportable bamboo hut and common toilets and water supply. But anyhow these huts should be organized in the proposed urban layout because it is very common that "temporary" becomes "everlasting". The proposed bamboo hut has a basic module of $3^{\prime} 4 "(\sim 1 \mathrm{~m})$. A human minimum should be $3 \times 6(=4+2) \mathrm{m}$ for a family of 5 members- but in reality it is often even less.

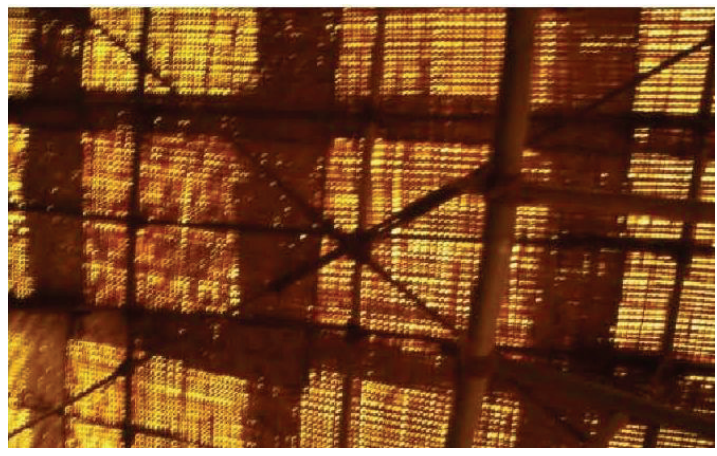

Of course other variations are also possibledepending on the plot and the facilities. The materials are bamboo for the structure, chattai (bamboo-mats) for the walls and plastic (light colour) or tiles for the roof. The hut is easily transportable; the users can shift within a day or two. Later, it can be converted into a permanent hut.

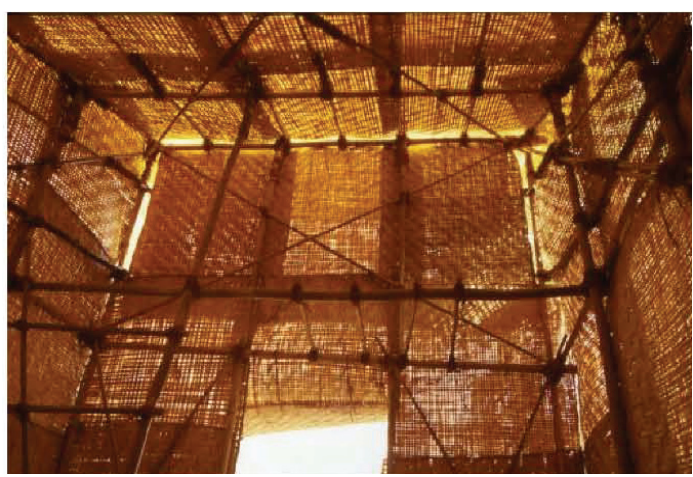

\section{PERMANENT SETTLEMENTS}

If there is a permanent settlement the bamboo hut can be the first step. Under ideal conditions foundation, toilet, water supply and electricity are already given. But in reality there often will be none of it in the beginning. In this case you start with the bamboo hut and variant $\mathrm{A}$ if possible. Depending on the political will and the finances the site can get developed. The hut develops from a bamboo structure to a brick house with $1 \frac{1}{2}$ floors. In this phase the hut has a roof with tiles. Very common are also asbestos cement sheets. They are self-supporting and very cheap but not good for health and climate. Yet there is no iron column or RCC.

But the foundation for a column should already be done for later. We also have to take care of the detailing of the wall. Small "I" section hold fasts are embedded in the wall during construction.

They can be connected later to a column, so that they form together a structure. In the normal building process there is first the column with small "I" hold fasts in the bricks. Here we change the order to keep the opportunity. And this is not much more expensive at this point of time.

In the third step the first floor is built. Iron columns carry the slab of the first floor but the roof is still a cement sheet or better tiles. For protection against corrosion the iron column is inside the hut.
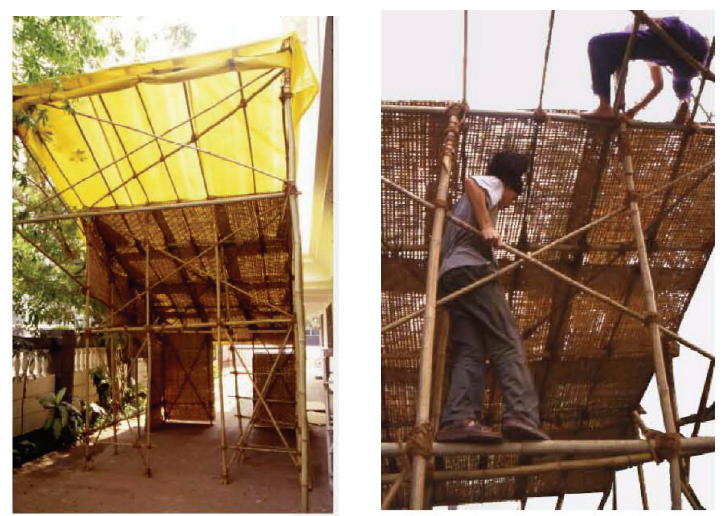

In the fourth step there are also iron columns in the first floor which carry a horizontal cement roof. This is important because the new terrace on the roof is usable space. It can be used as working space but also for sleeping or living. There is also 
the place for a water tank. Now the bamboo structure with the roof from the first step can be used again for monsoon protection, shadow and wind collection.

To have a nice character in the settlements they should be painted regularly very colourful- like in the seaface community.

The development is from case to case a bit different. Perhaps there might be one step more or less.

Of course we have to face the problem that most of the existing squatter settlements in Bombay are built in variant $\mathrm{C}$. to allow airflow in these hats you can keep some bricks open and cover them with curtain for view protection. But in this case you have less privacy. Perhaps you can organize it sometimes to shift some of the inhabitants a little to have two smaller families out of a big family together- separated by a door inside the two hats.

\section{REALIZATION OF THE HOUSES}

In the past there were already lots of programs. Most of them failed. It is important to know how to avoid the same failure.

In the "slum improvement program" (sip) they were given basic amenities like e.g. common toilets, water taps, street lights, open drains and paving of lanes between the hats. The main drawback was that the land tenure and shelter security was not there. Why should anybody improve the situation if he/she can be thrown out of area the same day?

Another trial was the "slum upgradation program" (sup). The security of tenure was granted- with a monthly rent. The slum people had to organize themselves in co-operatives. They got the permission of upgrading the condition of their old hats but not of rebuilding it in rcc and bricks. The problem of this program is the fact that the slum character and the social status of the slum dwellers did not change. Furthermore there was no improvement of the hygienic conditions.

In the site- and service program (ssp) poor people got a plot for free in an area with proper town planning standards and a credit with a soft loan from the World Bank. There were constructed very simple houses with conventional materials and basic facilities. But housing is such a big demand in Bombay that the poor sold their houses in underhand deals and returned to the slums. The real profit was made by middleman who exploited the poor and the community.

The "prime minister grant program" (pmgp) gave a lot of money to improve the infrastructure in slums- especially in Dharavi, the biggest slum of Asia. But of course this money was exhausted one day.

The "slum redevelopment and rehabilitation program" (srd\&d) proposes to grant higher "floor area ratio" (far) and "floor space index" (fsi). Half of the land is used for rebuilding and rehabilitating squatter people in regular multistoried high-density and high far/fsi-buildings. The other half is exploited for the open market. From this profit the first half is built for free. The aim is to flood the market and bring the real estate prices down. But often there are created only new, vertical slums. Sometimes the distance between two five-storieshouses is only four meter. For the moment the situation seems to become a little better, but you hardly can improve the situation in a couple of years. You create high-rise high density which creates very often a very high explosive social situation. In Europe these kinds of areas have been build in the sixties and seventies- but with lower density. In some of these areas the situation got so explosive and dangerous that the only way out of this was to blast the houses away and to shift the inhabitants to other areas.

For the proposed housing system the site- and service program can be a model- with some modifications of course. The settlers should get the plot with a paper for land tenure. This can be a lease for example 30,50 , or 99 years with a monthly rent. This right can be passed on the children or married people but it cannot be sold. But if they are sold the tenure comes to an end and the plot including the house comes back to the city or the state. For assuring this there should be regularly controls.

For the construction of the house there should be a credit with soft interests from the World Bank, the state of Maharashtra or private organizations; the inhabitants can develop their house at once or step by step. 


\section{NEEDS OF THE WHOLE CITY AND THE COUNTRY}

The problem of the slums and squatters in Bombay cannot be solved by this proposed modular housing system. There are further requirements for the whole city and country like to deal with poverty, illiteracy, the growing of the population, the cast system, corruption and pollution. Furthermore the surrounding of Bombay, but also the whole country has to be developed to stop people coming to Bombay. If they have at least equal chances elsewhere they do not come to Bombay.

In the city itself you have to try to pull down the real estate prices. You can make this for instance by building two or three further bridges between Bombay and new Bombay. This can be a very large bridge- a sign for Bombay, a "gateway of India of the $21^{\text {st }}$ century". It should be possible to reach New Bombay in twenty minutes from CST/ VT or Dadar. If the people are faster in New Bombay than for instance in Bandra or Andheri they will shift over there and the prices will adjust on a lower lever over the whole city.

\section{FUTURE SCENARIO: INDUSTRIAL PREFABRICATION WITH BAMBOO}

Due to the growth of population and to the increasing of human wants the need for raw materials will increase in the presence and in the future. The sources are limited, so the costs jump up. One solution to this problem can be the industrial use of fast growing materials like bamboo. What is more, the local economy will create jobs.

\section{ACKNOWLEDGMENT}

Thanks to the Director of Rizvi College of Architecture, Mr. Akhtar Chauhan who supported the development of this article.

\section{REFERENCES}

[1] Interviews of the author with settlers of Jafar Baba and Seaface Community in Mumbai/ Bandra in 2001/ 02

[2] "Build your House to the Rhythm of Life" from Bharat Jan Gyan Vigyan Jatha National Organising Council

[3] "Bombay- the cities within" by Sharda Dwivedi, India Book House, 1995

[4] "housing \& urbanisation" by Charles Correa, Urban Design Research Institute 1999

[5] "Grow your own House", Vitra Design Museum

[6] parts of this article has been published in the abstracts of the "4th international conference on humane habitat" in 2002, hosted by Rizvi College of Architecture in Mumbai, India. 